\title{
Professional Development Program for Technology Integration: Facilitators and Barriers to Sustainable Implementation
}

\author{
Albena Todorova ${ }^{1}$, Thomas Osburg ${ }^{2}$ \\ University of Munich (LMU) ${ }^{1}$, Intel Corp. ${ }^{2}$, Germany \\ albena.todorova@psy.lmu.de \\ thomas.osburg@intel.com
}

\begin{abstract}
The question which factors determine the long-term effect of programs and initiatives for improving teachers' technical and methodological competencies for integrating technology in the classroom is discussed in the context of the teacher professional development program "Intel Teach - Advanced Online". The external evaluation of the program provides evidence about the factors on personal, school and system level, which contribute to or impede the sustainability and successful implementation of the program. The analysis the findings points at some areas for improvement, such as the communication and presentation of the program, its character and outcomes; the role of school tutors and leadership, but also factors to capitalize on, such as the collaborative work of teachers. Understanding the comprehensive set of factors and how they affect the success and sustainability of a program is advantageous not only for the enhancement of the presented professional development, but for planning similar initiatives as well.
\end{abstract}

\section{Introduction}

The recent evidence of persistent high demand for teacher professional development in the area of technology-enhanced teaching and learning [1] raises the question which factors determine the long-term effect of programs and initiatives for improving teachers' technical and methodological competencies for integrating technology in the classroom. The successful adoption of new practices by teachers and obtaining positive outcomes and acceptance of a program for professional development are to a large extent determined by its design and implementation. Maintaining positive outcomes over time, however, is also influenced by the participants and by the conditions in which the program is carried out. Improving the sustainability of a program for teacher professional development therefore is directly related to following effective design principles and to understanding and influencing the external factors in the specific context of its implementation. Assessing how characteristics of the program, the participants and the context impact its effectiveness and outcomes provides means for preventing or counteracting negative influences of the context and for strengthening and capitalizing on positive conditions.

Research in the last two decades has yielded consistent evidence for the factors and components, which contribute to effective teacher professional development in use of technology. Effective programs are sustained over time, have at their core professional learning teams for collaboration, involve teachers in solving authentic problems related to teaching and learning, deepen teachers' pedagogical skills and include opportunities for practice, research and reflection [2]. Successful professional development programs are aimed at the improvement of student performance, involve teachers in determining the focus of their learning and provide them with learning opportunities that are school-based, continuous and supported, information rich, and facilitating theoretical understanding and collaborative problem solving [3]. Integration of technology in the classroom is also strongly influenced by the external support for teachers, their access to up-to-date resources and participation in a community of teachers working with technology [4].

Effective teacher professional development is only one of several necessary but not sufficient conditions underlying sustainable innovative teaching practices using technology [5]. Further conditions are teacher, student and administrative support, as well as the perceived value of innovation [5]. Funding, teachers who drive innovation, support within and outside school, as well as supportive plans and policies are all conditions, which contribute to the sustainability of technology-based educational change. Specific role have the unique attributes of technology, such as costs and maintenance, rapidly changing nature and specialized knowledge and skills required [6]. From a more general perspective, sustainability in educational 
change involves maintaining improvement over time, learning gains for everyone, and not only a few, support by attainable or available resources, and opportunities for diverse solutions and flexibility [7]. Additional elements seen as essential for sustainability of technology-based innovation are culture of learning at all levels of a system and leaders who drive the change [8].

In summary, key design components of effective professional development programs are opportunities to learn and practice innovative approaches over prolonged time, to work collaboratively on authentic tasks and to influence the choice of activities toward addressing the individual learning needs of teachers. At the same time a program based on these principles becomes sustainable only if there are advantageous conditions, such as support by teachers, students and administration, from outside school and through plans and policies, leaders or teachers who drive the innovation, available resources and appreciation of the direction of change.

Against this background, the factors which influence the successful implementation and sustainability of a professional development program are specific in every case and actions for improvement can be taken only after assessment of the specific context and system. Focus of this paper are the findings from the evaluation of the teacher professional development program for integrating technology in the classroom "Intel® Teach - Advanced Online", and particularly the identified factors for its sustainability. The program was developed based on established effective design principles and its quality assurance evaluation showed highly positive outcomes. However, the different patterns and effectiveness in the contexts in which the program was implemented revealed its strong dependence on external factors. The qualitative investigation of these factors points at areas, which can be influenced in order to improve the sustainability of the program and its impact. The results of the external evaluation of the program have been reported in detail in the official reports [9], [10]. The aim of this paper is to discuss the findings in the context of the program design and to outline possible measures for improvement. For this purpose it will provide an overview of the design and implementation of the program, summary of the evaluation findings and implications for its improvement.

\section{Intel Teach - Advanced Online}

\subsection{Design and Implementation}

The teacher professional development program "Intel Teach - Advanced Online" is one of the projects, designed and implemented within the Intel ${ }^{\circledR}$ Education Initiative of Intel Corp. for the advancement of education through technology. Programs within the initiative comprise of teacher professional development projects, formal and informal technology-enhanced learning opportunities for students, science and technology competitions and talent search, and higher education projects.

One of the main components of the initiative is the Intel ${ }^{\circledR}$ Teach Program - a program for professional development aimed at training classroom teachers to effectively integrate technology in instruction to enhance student learning, developed in collaboration with Ministries of Education and educational institutions. The program is provided to elementary and secondary school teachers around the world and encompasses a portfolio of courses targeting different aspects of integrating technology in classroom teaching, such as classroom software productivity tools and student-centred approaches to learning; integrating technology into existing classroom curricula; using online tools to enhance students' higher order thinking skills; and advancing teachers' methodological skills.

The program "Intel Teach - Advanced Online" ("Intel ${ }^{\circledR}$ Lehren - Aufbaukurs Online”) was developed in Germany, following the successful implementation of a basic course for technology use in teaching within the Intel Teach Program. The concept for the advanced course was developed by the Academy for Teacher Training and Human Resources Management in Dillingen (Akademie für Lehrerfortbildung und Personalführung, ALP) - a state-owned teacher training centre belonging to the Ministry of Education in Bavaria, Germany [11]. The program was subsequently localized and implemented in England, France, Ireland, Israel, Italy and Jordan. It is based on a blended learning format of face-to-face meetings and individual and collaborative learning supported by an online platform, which enables self-paced on-the-job professional development. Participants in the program are guided and assisted in the training process by mentors (Master Teachers), who have expressed interest to become mentors and have received special training for the program by Senior Trainers (Landesmentoren), responsible for the implementation of the program in different federal states. This "trainthe-trainer” approach enables a high degree of support, 
through the presence of mentors in the schools and communities of the participants in the program.

The professional development process in "Intel Teach - Advanced Online” follows a step approach. After registration for the program teachers are introduced to the concept and content by a trainer in a face-to-face meeting. The next steps include using the online platform to study the available methodological information for integrating technology in a learnercentred classroom and example materials, and discussing in groups the requirements and objectives of the training. Teachers select a focus for their training from the possibilities available on the online platform (Figure 1), based on their personal professional needs. This pedagogical framework is called 'Learning Path' and within it teachers use a selected pedagogical approach or certain technological tool to develop a unit plan, implement it in their classroom practice, evaluate it and enhance it for further use.

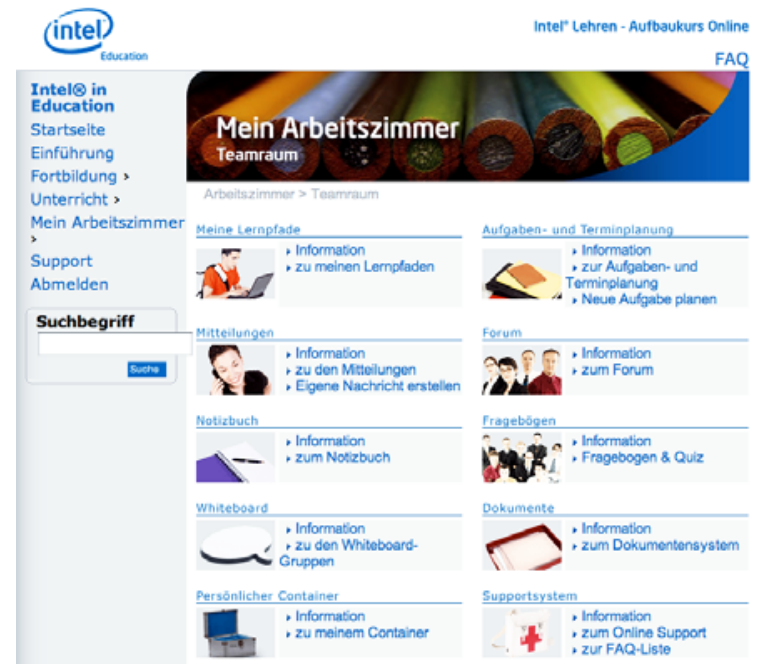

Figure 1. Online platform of the program "Intel Teach Advanced Online" in Germany

Every learning path is either driven by its pedagogical approach or by the application of specific digital media, e.g. data handling and data analysis; using digital technology to allow students to work collaboratively online. Learning paths can be chosen by subject, by concept (e.g. task-oriented, inquiry, hands-on, etc.), by various teaching methods and learning styles. The program curriculum consists of a minimum of one learning path, while the participant teachers are free to choose to work on more paths. The intended distribution of time for completing a Learning path is 8 hours for introduction to the concepts, methods and technology, 12 hours for working on a Learning path collaboratively with other teachers, and
20 hours of individual learning using the available online resources and tools. The platform includes several main areas to suit personalized needs: areas for work with the learning path and areas with resources, collaborative tools, additional information and online support (Figure 1). The platform uses simple open source tools by collating and making available open source and free software tools to enable material creation. Using the training platform is flexible and teachers have the choice to participate in the training from home or from school, depending on their preference and technology availability. Teachers also can access the platform after they have completed the program and use the available resources, ideas, unit plans and materials for self-directed learning.

In order to complete the chosen learning path, teachers work collaboratively with other teachers. The majority of their learning is done either in collaboration with their team, or individually, and is extended over a period of time. When teachers develop an effective method that is working very well in their teaching and has shown good results with their students, they are encouraged to share it through fitting the method within the pedagogical template and then positing it on the platform for other teachers to benefit from. Teachers also evaluate their learning individually and collaboratively and plan for further enhancement and extension, which provides them at the same time with knowledge how to embed research and continuous evaluation in their day-to-day teaching.

\subsection{Evaluation}

The programs of Intel Teach are subject to systematic external evaluation for determining the direct effects of the training. The evaluation of the implementation of "Intel Teach - Advanced Online" in Germany in the period from 2005 to 2008 was conducted by the Institute for Media and Educational Technology in the University of Augsburg [9]. The main aim of the evaluation was to provide information base for the continuous improvement of the program and the focus shifted from quality assurance in the earlier phases of implementation toward sustainability [10]. The first phase of the program evaluation was based on an online, self-report end-of-training survey of teachers who complete the program, self-report surveys of mentors and surveys of teachers and university students at the educational fair Didacta 2006. Overall, the evaluation findings as reported in detail elsewhere [9], showed that the program has a positive impact on teacher attitudes, competencies and practices of classroom technology integration. Fourfifths of all participants declare that they have more 
ideas how to use digital media in their teaching. Nearly three-fourths of them significantly increased their confidence to use new media in the classroom and would recommend "Intel Teach - Advanced Online" to other teachers. Regarding the impact on their practice, teachers report slight improvement of the quality of their teaching. Regarding the indirect effect of the program on students, teachers report increased motivation in technology-enhanced classes, higher interest and participation of students in the lesson, increase in students' support and self-organization during team learning and improvement in students' skills for digital media use.

A preliminary investigation for determining the conditions of the program implementation in the different federal states included online questionnaire of open questions sent to the Senior Trainers. The findings showed that the effectiveness of the program could not be improved only through changes in the program design. In order to determine the external factors influencing the success of the program and its sustainability, as next phase of the external evaluation the Institute for Media and Educational Technology in the University of Augsburg conducted case studies of schools in four federal states in Germany, combined with interviews and group discussions.

\section{Factors for Sustainability}

\subsection{Concept}

The external evaluation of the sustainability of the program "Intel Teach - Advanced Online" is based on the premise that in regard to educational innovations in schools the term "sustainability" is used to describe the level of success of the implementation of new instructional or learning models, new professional development concepts, new content or technologies [10]. In the case of the program "Intel Teach Advanced online", the evaluation concept reflects the difference between the conditions on the level of the individual school and on the level of the school system, which impact the implementation of the program [10]. According to Häuptle, Florian and Reinmann (2008), on the level of the individual school sustainability of a teacher professional development program represents the degree to which the program produces changes locally. Here it is differentiated between improvement of teaching practices, staff development and organizational development (Figure 2). Sustainability in the first two areas is demonstrated when participating teachers achieve a lasting improvement of their competencies and teaching, and when a large proportion of the teachers in a school have participated in the program, form a community of practice and increase the collaborative work in the school for integrating digital media in teaching. Sustainability in regard to organizational development is evidenced by adoption of direction toward technology integration as a regular part of the educational practice. This is realized not only through improvement of the teaching and the staff, but also of the technical infrastructure, time restraints, class size, conditions, school focus and support from school mentors and leadership.

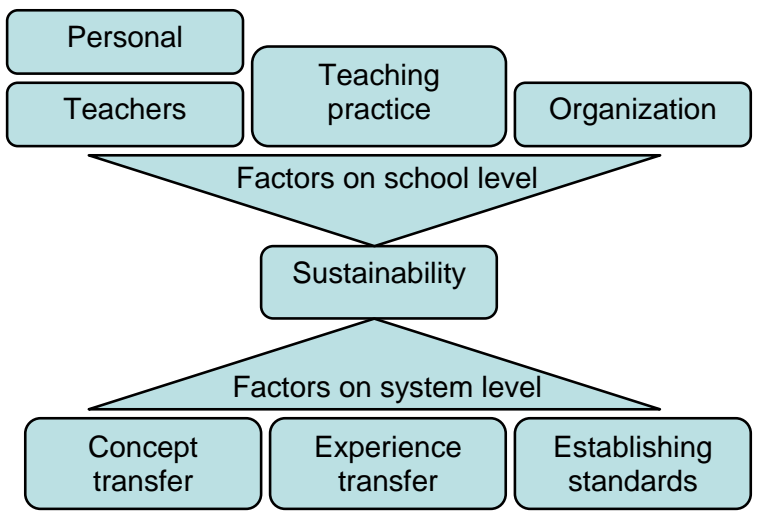

Figure 2. Factors for the sustainability of the program "Intel Teach - Advanced Online" (based on Häuptle, Florian and Reinmann, 2008)

On system level sustainability of a professional development program is demonstrated by the extent to which the professional development concept is accepted and implemented by different schools in an administrative region regularly [10]. Transfer of the concept is evidenced by participation of teachers from a large number of schools, teachers' positive attitudes and satisfaction with the course, availability of support and transfer of the goals, content and methodology of the program. The implementation of the program is facilitated when the authorities provide support for it, integrate it in the structure of professional development and are directly engaged in its promotion. Sustainability is also demonstrated when transfer of experiences occurs. In this regard a program is sustainable when the experiences of the participants, as well as the facilitating and hindering practices are recorded and used in the further implementation and improvement of the program. Additional evidence for sustainability is the establishing of standards for the implementation of the professional development program in schools through practice-derived systematic procedures. 


\subsection{Method}

The study was conducted in 2007 and 2008 by the Institute for Media and Educational Technology in the University of Augsburg. The sustainability of the program "Intel Teach - Advanced Online" was examined though case studies of 16 schools in four federal states in Germany [10]. Target population were teachers in the schools who participated in the program $(n=40)$, teachers who did not participate in the program $(n=24)$ and school principals $(n=15)$. The chosen federal states represent different policies of federal education authorities regarding the use of mentors for the implementation of the program. Thus, states supporting (Bavaria, Thueringen) and not supporting (Rheinland-Pfalz and Hamburg) regional and regionwide mentorship concept were included. Schools were contacted through the mentors responsible for the program on federal state level. Participation in the study was voluntary. Case studies were conducted on 16 schools. Individual interviews with school mentors and school principals, and group discussion with participant and non-participant teachers were conducted in 14 schools. The majority of the interviewed teachers had completed the program one or two years prior to the study.

The interviews included questions concerning professional development in general and inquiring about experiences with the school-based implementation of the program and the online platform, as well as about the learning gains and transfer. Further questions explored the school context in terms of experiences and conditions for collaboration with other teachers, and understanding of the concepts of learner-centred instruction, integration of digital media and the conditions for their effective use. Questions regarding the program "Intel Teach Advanced Online" inquired about the reasons for participation or non-participation, procedures followed during the implementation of the program, the role of the school leadership, the conditions in the school, satisfaction with the program and benefits from participating in it, advantages of the blended learning format, suggestions for improvement and further use of the program.

The analysis of the interviews and group discussions was conducted separately by school and federal state. From the resulted categories and subcategories, the ones, which were found in all schools in a federal state and in all federal states were summarized. In order to validate the findings, they were presented to and discussed with the respective participants in the study in two schools in RheinlandPfalz. The discussions confirmed the results from the data analysis. Additionally, the opinions of Senior Trainers from twelve federal states were collected through group discussions and written comments. Senior Trainers are an important source of information regarding the sustainability of the program, due to the fact that the program has been coordinated and implemented differently in the individual federal states in Germany. This additional perspective allowed the confirmation or adjustment of the interpretation of certain factors.

\subsection{Results}

The findings from the external evaluation reported in detail by Häuptle, Florian and Reinmann (2008) provide evidence for the facilitators and barriers to the sustainable implementation of the program "Intel Teach - Advanced Online” [10]. Regarding teacherrelated factors, advantageous personal conditions were positive experiences with the basic course offered prior to the advanced program, and with software packages. Further facilitators were the consequent deepening of the competencies acquired during the basic course and inclination to and interest in digital media. One of the motives of teachers not to participate in the program was the lack or insufficient experience with digital media. In individual cases teachers were discouraged to use technology in class after being confronted with students with advanced media competencies or on the contrary, with students who were overburdened during technology-enhanced learner-centred classes. Further impeding factors were the lack of interest in the objectives of the program, uncertainty of the added value of the program, and low relevance for career advancement of the certification obtained in the program. Beneficial faculty-related factors at the level of the individual school were teachers' positive experiences from collaborating with colleagues, good organization of and available time for teamwork. Collaboration with same-subject teachers was seen as particularly satisfying. Teamwork was in some cases continued after completion of the program, however limitations in terms of organization and time impacted the sustainability of teacher collaboration.

Regarding teaching practices, teachers' acceptance of the didactical concept, perceived learning gain, engaging in reflection on their own teaching, and experiences with the added value of digital media in teaching positively influenced the implementation of the program. A certain ceiling effect was observed among the teachers, who were already experienced and confident in using digital media prior to participating in the program. In these cases teachers indicated only small learning gains from the professional 
development. Contrary to this, teachers with little experience and low confidence in using information and communication technologies and software reported higher learning gains, particularly when they were provided with sufficient support by the school mentors. Important consequence for the participants in the program was the improved understanding of the advantages of using technology in instruction compared to traditional teaching methods, such as the opportunities for internet research, for presentation and elaboration of the content with different media, for approaching certain topics in new ways, and for individualized learning.

Participants and non-participants in the program considered the lack of time for use of digital media an important barrier to the successful implementation and sustainability of the professional development offering. Teachers who did not take part in the program attributed it to lack of time. Participants in "Intel Teach - Advanced Online” indicated that investing more time in the preparation of classes integrating technology required high motivation, especially when the benefits from it were not so clear. Additionally, teachers stated that technology-supported group work, presentation of findings and direct feedback required more time in class, which impeded their implementation.

Further factors regarding teaching practices were the interest of students in learning with digital media and their prior knowledge and skills for using technology. Teachers reported that students showed higher interest in new forms of instruction and use of digital media in class. At the same time, participants had experiences with students who could not cope with learner-centred instruction and had insufficient skills for individual and self-directed learning and social skills. The use of computers combined with these methods of instruction is seen as suitable only in higher grades. Another barrier for integrating technology in class, according to teachers, is the large class size.

Organization-related factors had major impact on the implementation and the effectiveness of the program "Intel Teach - Advanced Online" in individual schools. Support by school mentors was identified as one of the facilitators for the success of the program. Advantageous conditions were the adjustment of the course by mentors according to the needs and qualifications of the participants, as well as regular face-to-face meetings. The statements of teachers who did not take part in the program or dropped out from it reveal the importance of communicating clearly the objectives and content of the program and informing and motivating teachers to participate.
The availability of technical infrastructure and maintenance was essential for the implementation of the program. Lack of computers, internet access and technical support impeded the readiness of teachers to integrate technology in class, and their interest in participating in the professional development. Insufficient infrastructure is also seen as a barrier to achieving learning benefits from technology-supported classes.

Decisive role had the support by the school leadership. Fostering the program through ensuring the necessary technical infrastructure and maintenance, providing time for collaboration and for innovative instruction, and integrating methods- and media competencies in the school priorities contributed to the sustainability of the program. When a school emphasized the use of new media for teaching and learning, this was related to better infrastructure, time availability and collaboration. Participation of a high number of teachers from a school in the program was related to provision of more time for instruction by the mentors and for collaborative work on projects, thus increasing the effectiveness of the professional development.

Factors at the level of the school system are grouped in three categories: concept transfer, experience transfer and establishing of standards. The notion of concept transfer relates to the evidence that schoolpolicy development in a federal state can be both beneficial and hampering. Factors for the sustainable implementation of the program in this group are related to the mechanisms for reaching teachers and for motivating them to participate in the professional development offering, as well as communicating the objectives and nature of the program effectively (Table 1). For instance, curricula providing for the integration of digital media in subject teaching increase the openness and readiness of teachers to participate in the program. With the adoption of requirements for professional development in some federal states and the introduction of professional development portfolios, e.g. in Hamburg, it is expected that teachers will use more often the opportunity to complete the "Inter Teach - Advanced Online" program.

One of the impeding factors for the sustainability of the program is the low value of the use of digital media in teaching in the school policies of the education authorities. In such cases after the end of a media project, the related activities and innovations are discontinued. At the same time, if such gap is acknowledged, the implementation of the program in such conditions can help to improve the situation.

Informing teachers about the offering of "Intel Teach - Advanced Online” and stimulating their 
interest in participating in the program are improved when education authorities are directly involved in promoting the program. Such positive influence is observed also when the program is offered in flexible formats, accounting for teachers' needs. Using different channels to inform teachers about the program is found to be advantageous as well, especially when the offering is presented through official communications of the education authorities and professional development institutes, such as direct mail, newsletters and portals.

Table 1. Beneficial $(\lambda)$ and impeding $(\nabla)$ factors regarding the concept transfer on the level of the school system (based on Häuptle, Florian and Reinmann, 2008)

\section{Factors related to school policy}

$\lambda$ Digital media is a component of the curriculum and lesson plans

$\pi$ Higher school autonomy

$\pi$ External evaluation for quality development

$\lambda$ Demand due to professional development requirements

$\searrow$ Policies place low value on the use of digital media in teaching

$\checkmark$ High workload due to restructuring of the work

$\searrow$ Involvement in training according to needs

Factors related to reaching the target population

$\pi$ Alignment of the program with the objectives for professional development in a federal state

$\lambda$ Use of flexibility and creativity

$\pi$ Mentors integrate different functions

$\pi$ Teachers are well informed about the program

$\pi$ Reaching the group of teachers not interested in technology

$\lambda$ Recommendation of the program on the base of positive experiences

$\searrow$ Objectives of the program do not represent current school policy of the federal state

$\checkmark$ Demand regulates the frequency and place of information meetings about the program

Factors related to the program presentation

$\pi$ Stimulate interest with presentation of specific content

$\pi$ Preparation of the school mentors for their role

$\checkmark$ Insufficient staff to organize program presentations

$\checkmark$ Absence of mentors

The evaluation provides important evidence for effective ways to approach teachers, who are not interested in using technology in class. Reaching this group of teachers was accomplished through clear communication of the goals of the program and the advantages from participating in it, removing the negative attitudes toward technology, and indirect pressure through teaching quality control, such as school evaluation practices.

The absence of state education policies for integration of technology in instruction was an impeding factor for reaching teachers and stimulating their participation in the program. This aspect of the implementation of the professional development was also negatively influenced by the practice of organizing information meetings according to requests by schools, rather than on a systematic base. Such information meetings were effective when the benefits of participating in the program were exemplified with specific lesson plans, such as the plans on the online platform, and when the content was related to currently interesting topics for teachers, e.g. how the program supports teachers in the implementation of school policies regarding education standards, media competencies, self-evaluation and others. Important role for the success of these meetings had the preparation of school mentors for presenting the program, whereas the lack of support by Senior Trainers and the lack of school mentors to drive the implementation of the program in the individual schools limited the potential of information meetings for motivating teachers to participate in professional development.

In the context of experience transfer, sharing of practices between schools was not supported in the federal states, which tool part in the study. Sharing of experience, which affected the sustainability and successful implementation of the program was realized within schools as continuation of the teamwork during the program. The last factor on system level is the establishment of standards, which relates to the systematic implementation of professional development requirements and technology integration policies within and across federal states. Due to the differences in federal policies, school autonomy and conditions in schools, the transfer of experience and the establishment of standards cannot be influenced to a degree to improve the sustainability of the program. This can be achieved mainly through influencing the factors related to concept transfer.

\section{Discussion and Conclusions}

Identifying the factors, which contribute or on the contrary, impede the sustainability of a professional development program, allows to draw a comprehensive outline of the beneficial external conditions which can be strengthened, and the negative conditions which can be improved. Although certain elements of the specific context in Germany, such as federalism and large 
differences in regional policies and practices, cannot be changed, some factors in the area of concept transfer and on school level can be easily influenced in order to improve the sustainability of the program and its further implementation. Firstly, communicating the character, prerequisites and outcomes of the program in a clear way and to a broader audience of teachers and school principals can have a considerable positive effect. Similarly, the example of tutors and participating teachers and their attitude and satisfaction with the program has a strong influence on the interest of teachers, who have not participated in this professional development offering. Strengthening the presentation of the program to teachers with demonstrations of the learning process and the available resources and support can increase teachers' interest and participation rate. However, the exact way to realize that in a way accepted positively by teachers in not clear. Further investigation of teachers' preferences for media and format of such communication and presentation of the program, for instance online or face-to-face, can contribute to the planning of measures for improvement.

Second group of factors, which can be positively influenced, is related to the school organization and the role of tutors and school principals for the successful implementation and maintenance of the program. Actions in this direction can be stimulating more teachers to take the role of tutors through incentives, as well as providing more information to school leadership about the positive findings of the program evaluation about improved teacher competencies, increased use of technology-enhanced learner-centred teaching, and higher student motivation and interest. The importance of effective teamwork during participation in the program can also be capitalized on, through improving the conditions and support for collaborative work within the program design.

The outlined findings and implications about factors which influence the sustainability of the teacher professional development program "Intel Teach Advanced Online" provide limited evidence for generalization. However, it can be speculated that a similar program for technology integration will be affected in a similar way by the contextual conditions if implemented in Germany. In this respect understanding the comprehensive set of factors and how they contribute or impede the success and sustainability of a program can be advantageous for future planning of such initiatives. Thus, improving teacher professional development offerings will be more successful if it includes not only design and implementation adjustments, but also measures to influence the context.

\section{References}

[1] OECD, "Creating Effective Teaching and Learning Environments: First Results from TALIS”, 2009, www.oecd.org/edu/talis/firstresults

[2] K. A. Lawless and J. W. Pellegrino, "Professional development in integrating technology into teaching and learning: knowns, unknowns, and ways to pursue better questions and answers", Review of Educational Research, 77(4), 2007, pp. 575-614.

[3] W.D. Hawley and L. Valli, "The Essentials of Effective Professional Development a new consensus". In: DarlingHammond, L., Sykes, G. (eds.) Teaching as the Learning Profession: handbook of policy and practice, pp.127--150. San Francisco: Jossey-Bass, 1999.

[4] E.S. Pianfetti, "Teachers and technology: digital literacy through professional development”, Language Arts, 78 (3), 2001, pp. 255-262.

[5] R. D. Owston, "Contextual factors that sustain innovative pedagogical practice using technology: An international study”, Journal of Educational Change, 8(1), 2007, pp. 6177.

[6] C. Dede (Ed.), Learning with technology. Alexandria, VA: Association for Supervision and Curriculum Development, 1998

[7] A. Hargreaves and D. Fink, "Three dimensions of reform”, Educational Leadership, 57(7), 2000, pp. 30-34.

[8] M. Fullan, Leadership \& sustainability: System thinkers in action. Thousand Oaks, CA:Corwin Press, 2005.

[9] A. Ganz and G. Reinmann, "Blended Learning in der Lehrerfortbildung - Evaluation einer Fortbildungsinitiative zum Einsatz digitaler Medien im Fachunterricht“, Unterrichtswissenschaft, 35(2), 2007, pp. 169-191.

[10] E., Häuptle, A. Florian, and G. Reinmann, "Nachhaltigkeit von Medienprojekten in der Lehrerfortbildung. Abschlussbericht zur Evaluation des Blended Learning-Lehrerfortbildungsprogramms „Intel $\AA$ Lehren - Aufbaukurs Online“ (Arbeitsbericht Nr. 20)”, Augsburg: Universitaet Augsburg, 2008.

[11] S. Aufenanger, "Evaluation der Pilotphase von "Intel Lehren fuer die Zukunft - Aufbaukurs” (Intel II-Projekt): Abschlussbericht“, Hamburg: Universitaet Hamburg, 2004. 